\title{
Connecting Twenty-first Century Skills and World Language Practices: A Case Study with Teachers of Critical Need Languages
}

\author{
Marjorie Hall Haley \\ George Mason University, USA \\ Sherry L. Steeley \\ Georgetown University, USA \\ Maryam Salahshoor \\ George Mason University, USA
}

\begin{abstract}
This mixed method study investigated 25 pre- and in-service teachers (12 Arabic and 13 Chinese) who attended a 2012 StarTalk Summer Institute (STSI). The current study took place over the course of two weeks followed by three fall workshops. Through a carefully designed sequence of blended learning activities, 25 pre- and in-service Chinese and Arabic teachers were offered multiple opportunities to explore and examine teaching in a learner-centered classroom utilizing 21st Century Skills. Data were gathered during the summer institute using on-line surveys, small group interviews, daily reflections, online discussion board threads on Ning (an online platform for people to create their own social networks), as well as materials created by the participants. The results of this study draw attention to some of the complexities that critical need language teachers face.
\end{abstract}

Index Terms - critical need languages, teacher development, $21^{\text {st }}$ century skills

\section{Introduction And ConteXt: The NeEd For CRitical Language Teachers}

During the last years of the $20^{\text {th }}$ century and the first decade of the $21^{\text {st }}$ Century, the importance of global understanding and intercultural communication in promoting national security, economic competiveness, and social well-being has become increasingly evident. In order to face the challenges of the 21 st Century and to effectively participate in today's globalized, knowledge-based economy, societies increasingly need individuals who can communicate globally and who are aware of the role of language and culture.

Two initiatives during the current decade have influenced language teaching in the United States. First, in January 2006, President George W. Bush introduced the "National Security Language Initiative" aimed at increasing the number of Americans learning world languages, particularly what the initiative referred to as "critical need" languages, including both Arabic and Chinese. Second, the Partnership for $21^{\text {st }}$ Century Skills (P21) outlined the key elements of teaching and learning focused on student outcomes. This focus quickly revealed an urgent need to better prepare teachers of these languages with commensurate support and funding. In addition, President Obama has made the expansion of world language capacity a central element in the Departments of State and Defense, explicitly tying world language skills to the national interest and emphasizing increased cooperation and understanding around the globalized, interconnected world (Obama, 2008).

As a result of this attention and funding through the National Security Language Initiative (NSLI), district offerings and student enrollment in critical need languages has risen rapidly. Comparing data from December 2002 with data from November 2011, enrollment in Chinese has increased 65 percent and Arabic enrollment 125 percent, among world languages with the highest growth rates (Homeland Security and Governmental Affairs Subcommittee, 2012). However, this rapid growth of Arabic and Chinese programs has been hampered by the shortage of "highly qualified" teachers who can provide standards-based instruction. The gap between the increasing growth of Chinese and Arabic language programs in K-12 public and private schools and the shortage of "highly qualified" teachers in these languages is great (Hui, 2012). According to U.S. Department of Education (2008), the certification of teachers of Arabic and Chinese languages as well as the development of standards-based curriculum and materials lag behind that of more commonly taught languages, such as French and Spanish.

Providing educational support to critical need language teachers, such as Chinese and Arabic, has been particularly challenging. World language teachers, many of whom have been educated in a non-western educational setting, encounter many cultural, pedagogical, and linguistic challenges as they transition into U.S. schools. Many times the single critical need language teacher within a school or district teaches diverse groups of students with various cultural 
and linguistic diversities but without the benefit of peer guidance and support. Another challenge critical need language teachers face is the lack of opportunities to access meaningful professional support; research has consistently shown that professional development, including mentoring and other forms of peer collaboration, has an important and positive effect on teacher effectiveness (Schrier, 1993).

In order to improve preparation of teachers in this critical need language area, a federally-funded initiative - StarTalk - was created and is administered by the National Foreign Language Center (NFLC) at the University of Maryland. StarTalk has offered more than 150 high-quality summer teacher training programs as well as student language learning programs in the critical need languages in 48 states and the District of Columbia both in K-16 settings and in heritage communities. It is expected that by the end of 2013, every state and territory in the United States will have at least one StarTalk program in one or more languages (Ingold \& Wang, 2010).

At the same time, The Partnership for $21^{\text {st }}$ (P21) Century Skills, a national organization that advocates for 21st Century readiness for every student, has developed tools to ensure that U.S. students develop skills in core academic subjects, including Social Studies, English, Math, Science, Geography, World Languages and the Arts. As the United States continues to compete in a global economy that demands innovation, P21 and its members provide tools and resources to help schools stay competitive by fusing reading, writing, and math and critical thinking and problem solving, communication, collaboration, and creativity and innovation. The $21^{\text {st }}$ Century Skills Map (2011) was developed through a year-long collaborative process, spear-headed by the American Council on the Teaching of Foreign Languages (ACTFL) and P21. The map reflects the efforts of hundreds of world language teachers and highlights the integration of World Languages and $21^{\text {st }}$ Century Skills. The map provides concrete examples of how $21^{\text {st }}$ Century Skills can be integrated into world languages.

Integrating these two policy areas of critical educational reform efforts, this case study focuses on the results of the StarTalk program's efforts to incorporate the $21^{\text {st }}$ Century Skills into the program of study of a cohort of Chinese and Arabic teachers who completed an intensive set of workshops in Summer-Fall 2012.

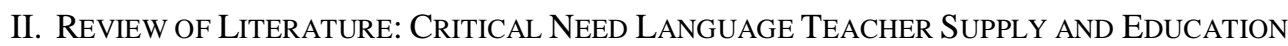

The existing literature reveals that there is an urgent need for more professionals with higher levels of proficiency in critical need languages in numerous fields, including national security to economic areas to translation and interpreting. Among a number of variables that affect student opportunities to learn critical need languages, the most significant is certainly an adequate supply of highly knowledgeable teachers and high-quality instructional materials. However, elementary and secondary school administrators who want to offer such languages report difficulty finding trained teachers and needed materials (Brecht, Golonka, Rivers, \& Hart, 2007). The problem of teacher shortage has been so severe that many school district representatives are traveling to China and to various Arabic-speaking countries to recruit teachers (Hall Haley \& Ferro, 2011). In fact, the vast majority of pre-service and in-service Chinese teachers who are teaching in K-12 Chinese language classrooms in the U.S. were previously educated in mainland China or Taiwan (Hui, 2012). Similarly, heritage learners and "heritage schools" provide another source of prospective teachers of critical need languages.

According to Schrier (1993), expanding the prospective language teacher pool to include these newly identified groups of individuals can help meet the demands for more teachers in critical need languages. Native speakers of critical need languages who grew up and attended schools outside the United Stated can bring very desirable characteristics to the teaching environment if they are well prepared to teach native English speakers in a K-12 environment. For example, the native speaker has a linguistic competency in the target language as well as firsthand cultural knowledge to share.

Several scholars have investigated the challenges that critical need language teachers educated in non-Western countries face as they transition into Western schools, a context that is extremely different from the culture and educational system in their countries of origin. These challenges may include language barriers, culture shock, different perceptions and expectations of the roles of the teacher and students, communication with parents, different beliefs about teaching, different pedagogies and styles, classroom management and discipline, the role of learners and the importance of self-regulated instruction, standards-based curriculum development and assessment, and inclusion of students with special linguistic, ethnic, cultural, and cognitive needs (Hui, 2012). In an attempt to better understand these issues, McNamara and Lewis (2004) surveyed teachers who were trained in non-Western educational settings but were teaching in the United Kingdom (UK) in order to determine what they found to be the most challenging. Among those teachers, they mentioned the importance of appropriate classroom discipline and behavior management, excessive paperwork, the heavy workload, the different teaching methods, and lack of familiarity with the National Curriculum and assessment system. Furthermore, because teaching a language is not only about teaching the language itself (Valdes, 1986), particularly because in a multicultural classroom in which teachers and students come from varied backgrounds, both may approach situations with different cultural values and expectations about their roles, making efficient and effective cross-cultural communication highly important.

Further, world language teaching can be a lonely occupation (Hammadou \& Bernhardt, 1987), but for the critical need language teacher it can mean total isolation. These teachers find themselves in an environment where they are faced with several immediate challenges without any peer support and guidance. This isolation is created by not only 
the subject matter being taught but also by the instructional delivery of these languages. Most often these teachers are in a unique situation of introducing a new language in an environment with previously-established professional structures and performance standards expectations from the commonly taught languages such as French or Latin (Schrier, 1993).

Another challenge critical need language teachers face is the lack of opportunities to access to meaningful clinical experiences. Research has consistently shown that professional development, including mentoring and other forms of peer collaboration, has an important and positive effect on teacher effectiveness (Schrier, 1993). Due to the shortage of qualified and certified world language teachers in the U.S., critical need language teachers often lack adequate training.

Thus, because only a limited number of world language education programs provide certification in the critical need languages (Hui, 2012), this sudden attention to, and funding for, language learning opportunities in critical need languages have quickly revealed that innovative means must be devised to locate, provide appropriate training for, and to accommodate the needs of teachers of less commonly taught languages, particularly those who may have been educated outside the United States. The present study addresses teachers' need to critically discuss cultural differences and to learn and apply theories, methods, and strategies for learner-centered instruction (Hall Haley, 2001; Hall Haley and Ferro, 2011). In particular, the study examined the way in which teachers of Chinese and Arabic successfully address $21^{\text {st }}$ Century Skills in the world language classroom and investigated the following research questions:

1. In what ways were the Arabic and Chinese teacher participants in the Summer-Fall Startalk workshops able to connect $21^{\text {st }}$ Century Skills to standards-based instructional practices?

2. How did teacher participants learn to utilize technology applications to implement $21^{\text {st }}$ Century Skills in today's world language classroom?

\section{THE STUDY}

In order to collect and analyze data that would shed light on these research questions, this study used a mixed method design that examined the perceptions of 25 pre- and in-service teachers (12 Arabic and 13 Chinese) who participated in five day-long professional development workshops at a 2012 StarTalk Summer Institute (STSI) and actively engaged in a weeklong online learning community that focused on learner-centered classrooms utilizing 21st Century skills. Through a carefully designed sequence of blended learning activities, these workshops provided participants with multiple opportunities to explore and reflect on the critical considerations that directly influence transitioning to teaching in a learner-centered classroom utilizing $21^{\text {st }}$ Century skills.

Thanks in large part to two generous grants, one from the Freeman Foundation and the other from StarTalk, the world language licensure program in our university has been able to sponsor five summer institutes (SI) for Arabic and Chinese teachers. The fifth SI which took place in 2012, is the focus of the present study. This two-week institute, "GMU StarTalk: 21st Century Skills - Implications for Teaching Critical Need Languages," is a follow-up and continuation of research reported in "Bridging Instructional Gaps in Preparing to Teach Millennial Learners," (Hall Haley \& Alsweel, 2012). The fifth SI focused on connecting critical need languages with the ACTFL $21^{\text {st }}$ Century Skills Map (2011). Since many of the participants have returned for each year's workshops, however, we have structured the institutes so that they are both scaffolded for returning participants, and review core principles for new attendees. Previous years have focused on multiple intelligences in language learning, cooperative learning in language learning, ACTFL Standards and planning outcomes-based lessons, and bridging cultural differences in U.S. classrooms. Thus, while these familiar themes spiral through both the onsite and online sessions, the primary goal for the 2012 institute was for participants to increase their understanding of the integration of standards-based instruction and the $21^{\text {st }}$ Century Skill Map and to develop culminating units that demonstrate that understanding.

\section{Participants}

Given the geographic location, the Startalk program examined by this case study was able to serve a large number of heritage speakers of Arabic and Chinese. The sample was purposeful in both the site and participant selection. Teacher participants completed an application for admission to the summer institute. Before the institute commenced, the researchers electronically corresponded with participants about the study to secure consent and conduct a pre-institute survey. The Program Director reviewed applications and decisions were made based on previous years of attendance, in-service or pre-service status, and an equal number of Arabic and Chinese teachers. The in-service teachers were from metro area public and private schools. Data were gathered on teachers' biographical and professional profiles, and their years of language teaching experiences. Of the 30 attendees, 25 teachers participated in the study. There were 22 females and 3 males. Participants' educational backgrounds varied widely. The demographics for the participants appear in Table 1.1. How many were new? How many returning? 
TABLE 1.1

Participant Demographics: Pre-Institute Survey

\begin{tabular}{|l|l|l|}
\hline Characteristics & Arabic (12) & Chinese (13) \\
\hline Mender & \multicolumn{2}{|l|}{} \\
\hline Female & 2 & 1 \\
\hline $\begin{array}{l}\text { Highest degree } \\
\text { earned }\end{array}$ & 10 & 12 \\
\hline Associate degree & 2 & \multicolumn{1}{|l|}{} \\
\hline Bachelor & 9 & 8 \\
\hline Master & 1 & 4 \\
\hline Doctorate & & 5 \\
\hline $\begin{array}{l}\text { In-service with } \\
\text { license }\end{array}$ & 2 & 8 \\
\hline $\begin{array}{l}\text { In-service with no } \\
\text { license }\end{array}$ & 10 & \\
\hline
\end{tabular}

\section{Instructional Activities}

A week before the 2012 Summer Institute, teachers engaged in a series of pre-institute readings, video viewings, and activities designed to introduce them to the $21^{\text {st }}$ Century Skills, while giving them background information that would be useful during the face-to-face meetings. During week one of the institute teachers met for five days of professional development workshops focused on learner-centered approaches to language teaching as highly effective tools for addressing pedagogical issues inherent in critical need languages. The workshops provided teachers with hands-on training in the introduction and application of interactive approaches in language teaching and learning. Participants attended professional development workshops in the morning that included individual sessions for Arabic and Chinese. In the afternoon, teachers participated in a series of language specific group activities led by master teachers, paying particular attention to the three Communicative Modes (Interpersonal, Interpretive, and Presentational). During the last two days of Week One, teachers were able to apply theory to practice, working on-site with language learners in Chinese and Arabic who volunteered for a simulated children's camp. Questions: did they produce anything we can analyze as data? Do we have HSRB permission to analyze their work products?

Week Two offered online blended learning activities using Ning as the platform, allowing teachers to further their participation in a community of learners. The discussion topics focused on the $21^{\text {st }}$ Century Skills Map, with a special focus on social and cross cultural skills, critical thinking and problem solving, leadership and responsibility, and media and technology literacy. Discussions and reflections focused on developing instructional activities based on the $21^{\text {st }}$ Century Skills Map (2011). For a culminating project, participants either aligned their newly created lessons to construct a $21^{\text {st }}$ Century Skills instructional packet or developed either an Integrated Performance Assessment (IPA) or a rubric for an IPA using the Skills Map.

\section{Procedures}

Pre- and in-service Arabic and Chinese teachers were recruited for the 2012 SI through a variety of channels including notices sent to local school departments and private schools with Arabic and/or Chinese language program. Pre-service teachers were recruited through our university where they were enrolled in a state-approved licensure program. There were 30 available seats in the institute.

Prior to the first day of the two-week institute, all 30 participants were sent an email that described the study, its purpose, and a link to SurveyMonkey (a private American company that enables users to create their own Web-based surveys) that contained the consent form and the pre-institute survey. Participation in the study was voluntary. To access the online pre-institute survey, the attendees had to first complete the online consent form. Completing the two online surveys took approximately 20 minutes each and participants were asked for permission to extract their responses from the discussion prompts and group interviews.

During the second week of the institute, the participants were required to engage in the online discussions. Each day the facilitator of the online portion of the institute posted several prompts to the Ning site that was developed specifically for the SI attendees. At the end of week two, the researchers extracted the responses to the online discussions that were posted.

On the last day of the 2012 SI, the 25 participants who consented to the study were emailed a link to the post-institute survey. The post-institute survey was also created using SurveyMonkey, utilizing the same design as the pre-institute survey. There were 25 participants who completed the survey.

\section{Data Collection}

A mixed method design was used to gather information about the perceptions of Chinese and Arabic teachers who participated in the 2012 SI concerning the connection between $21^{\text {st }}$ Century Skills to standards-based instructional practices. Data were collected from multiple sources: teacher's profiles, surveys, semi-structured and open-ended interviews, and field notes. The researchers examined the surveys, interviews, and observation data for themes that appeared across responses. The research instruments included a pre-and post-survey completed on line using SurveyMonkey. The group interviews with the participants were conducted in English and audiotaped with the 
participants' permission, ensuring their anonymity. The audio recordings were transcribed and then the data were coded and broken down by restricting them in new categories to allow themes to emerge.

Patton (2001) advocates the use of triangulation by stating "triangulation strengthens a study by combining methods. This can mean using several kinds of methods or data, including using both quantitative and qualitative approaches" (p. 247). Further, according to Johnson (1997), employing multiple methods such as observation, interviews and recordings will lead to more valid, reliable and diverse creation of realities. Member checking with other colleagues was employed to determine the accuracy of the qualitative findings. Most significantly, the final projects presented by participants were coded and analyzed to determine the extent to which they had been able to incorporate $21^{\text {st }}$ century skills into standards-based lesson planning. Researchers then used these data to compare participant perceptions of abilities with their demonstrated performance-based assessments.

\section{Instruments}

Pre- and Post-Institute Surveys. We created the pre-and post-institute surveys (see Appendix A for the instruments) using Survey Monkey. Our pre-survey consisted of 18 questions and the post-survey consisted of 25 questions. The first eight questions on both the pre-survey and the post-survey were identical and focused on the collection of demographic data. The pre-institute survey also had five multiple choice questions and five open-ended questions which asked participants to share their perceptions and previous knowledge regarding the way teachers should connect $21^{\text {st }}$ Century Skills to standard-based instructional practices.

The post-survey consisted of 5 multiple choice questions and 10 open-ended questions.

The multiple choice questions asked the participants to check the statements that best describe: their knowledge and understanding of the $21^{\text {st }}$ Century Skills, learner-centered instructional practices, ACTFL Standards of Foreign Language Learning (the 5Cs), the 3 Communicative Modes (interpretive, interpersonal, and presentational), and rate their concerns regarding teaching students in the U.S. The first five open-ended questions on the post-survey were identical to the pre-survey.

Post-Teaching Simulation Group Interview. Teachers were asked to participate in a post-teaching group interview (See Appendix B) and share how they planned and designed the activities for their lessons; whether their activities were connected to the standards; whether they were able to incorporate $21^{\text {st }}$ Century Skills in their lessons; how they used technology in their lesson; what worked well and what did not work well in their lesson; what would they do differently if they were to teach this lesson again; and what they learned about themselves as teachers and about the students in the United Sates.

Note: During the last two days of the Summer Institute the participants were to practice their newly acquired skills and participate in a two day formal teaching demonstration with volunteer students. However, due to a severe storm the last day was cancelled and the teachers only had one day of practice teaching with students.

Online Discussion Board - Ning. During week two of the SI, the participants engaged in online discussions by responding to daily discussion prompts posted by the facilitator on the social and networking platform of Ning (See Appendix C). There were a total of 13 prompts and teachers were asked to first view a short video clip regarding each topic and then answer 2-3 questions about the topic of that day. Discussion topics included: moving toward learnercentered instruction; applying standards and motivating students in a learner centered classroom; classroom management; millennial learners; cultural understanding of teacher roles; and personal and professional development answer the questions about the topic. In the next section we discuss the results of the research questions.

\section{Culminating Projects}

In addition to the intensive weeklong face-to-face workshops and practice teaching under the supervision of master teachers, the STARTALK SI included a week of online work in which participants synthesized and extended their learnings and teaching experiences. As a culminating project, participants developed either a unit plan or a performance-based assessment instrument integrating their learning on teaching methods from current and previous workshops, relevant technology resources, and the $21^{\text {st }}$ Century Skills. These projects provided an important point of analysis, reflecting synthesis of participant learnings and intended applications to their real teaching environments based on all of their other learnings in the Summer Institute. These projects were coded using both etic - researcher-provided - codes related to the curriculum objectives and $21^{\text {st }}$ century skills, and emic codes - those which arise naturally from examination of the data. Subsequently these comparatively analyzed against the results of participants reported knowledge gains to examine where there was a difference between belief and practice.

\section{RESULTS AND DISCUSSION}

\section{Research Question 1: In what ways do teachers connect $21^{\text {st }}$ Century Skills to standards-based instructional practices? \\ Participant Self-Perception. The pre-institute survey showed that $35 \%$ of the participants knew something about} how to connect $21^{\text {st }}$ Century Skills to instructional practices and $46 \%$ were able to describe their knowledge and understanding of learner-centered instructional practices. Furthermore, over half $(56 \%)$ of the teachers indicated that they had some knowledge and understanding of the Standards of Foreign Language Learning and the three Communicative Modes. The post-institute survey data revealed that the summer institute had a positive impact on the teachers' ability to plan activities that connect $21^{\text {st }}$ Century Skills to learner-centered approaches to teaching and 
learning. Of particular importance was the teachers participants' knowledge and understanding of the 21 st Century skills, the Standards of Foreign Language Learning (The 5Cs), and knowledge and understanding of the three Communicative Modes (interpretive, interpersonal, presentational) in addressing students' needs. The post-survey showed that $81 \%$ of participants stated that they had heard of the 21 st Century skills and felt that they were familiar with how to connect them to their standards-based instructional practices compared to $34.6 \%$ in the pre-institute survey data.

Analysis of post teaching group interviews revealed that for the majority of participants learning about how to connect the $21^{\text {st }}$ Century Skills was a new concept. Teachers were eager to explore the $21^{\text {st }}$ Century Skills Map and then make connections to align it to their daily teaching. When teachers did their practice teaching simulations with the children's camps, they had first-hand experiences of connecting theory to practice. We were pleasantly surprised to see the ease with which they handled this and implemented the Skills Map in creative and engaging activities.

One teacher commented, "I think our group was very successful. We stayed in the target language and did not use any English. And we were very careful about the language that we used. So one of the things in our PowerPoint showed a picture and we repeated the words over and over. We also used thumbs up and down before we asked the kids to say the words." Another teacher noted, "I am a new teacher so I feel like when you are planning something and when you are actually doing it, it is totally different. I have to think about every step and every sentence and about the flow of every activity. What I planned and what actually happened are very different." One teacher's response to the question, "What would you differently if you could teach this lesson again?" -- "If I had the chance to do the lesson again, I would like more time to rehearse before the class and maybe even work with the master teacher. I would have more control over the time. I also would like to design more activities where I can incorporate music.”

In both the post-teaching group interview and the post-institute survey, teachers discussed the theories and techniques they applied from the SI to their micro-teaching demonstration. The teachers noted that their learner-centered activities were connected to the $21^{\text {st }}$ Century Skills Map and they could incorporate cultural activities, foster collaboration, and provide thematic topics and global awareness in their lesson plans.

The following is a summary of the teachers' responses to question number one:

- We use them in creating our daily lesson plans

- $21^{\text {st }}$ Century Skills help design effective Integrated Performance Assessments

- They allow us to use more technology and thereby relate more to our students

- We can include the P21 skills map for all our lessons

- P21 skills allow us to develop a stronger cultural awareness of the target language

- $21^{\text {st }}$ Century Skills enable us to create appropriate formative assessments

- We can align the $21^{\text {st }}$ Century Skills to the Three Communicative Modes of Communication

- P21 skills can be incorporated in all our activities

- They provide a new way to embed the National Standards

- We have more ways to use authentic materials with our students

- We can use formative assessments more effectively now

- The P21 skills and Communicative Modes allow us to teach using real life experiences

- They allow students to practice and demonstrate their understanding of the content being learned

- The colors used in the Skills Map make it easy for us to follow and implement into our daily lessons. It is a simple graphic organizer.

Table 2.1 outlines the results of the pre- and post-survey that addressed our first research question.

TABLE 2.1

PRE AND POST-SURVEY RESULTS

\begin{tabular}{|c|c|c|c|c|c|c|}
\hline \multirow[b]{2}{*}{$\begin{array}{l}\text { Check the statement that best } \\
\text { describes your familiarity } \\
\text { with } 21 \text { st Century Skills }\end{array}$} & \multicolumn{2}{|c|}{$\begin{array}{l}\text { I have heard of } 21 \text { st Century } \\
\text { Skills and am familiar with how } \\
\text { to connect them to standards- } \\
\text { based instructional practices }\end{array}$} & \multicolumn{2}{|c|}{$\begin{array}{l}\text { I have heard of } 21 \text { st Century Skills } \\
\text { but I am not sure how to connect } \\
\text { them to standards-based } \\
\text { instructional practices }\end{array}$} & \multicolumn{2}{|c|}{$\begin{array}{l}\text { I have never heard of the } 21 \text { st } \\
\text { Century Skills }\end{array}$} \\
\hline & $\begin{array}{l}\text { Pre-survey } \\
34.6 \% \\
\end{array}$ & $\begin{array}{l}\text { Post-survey } \\
81 \% \\
\end{array}$ & $\begin{array}{l}\text { Pre-survey } \\
57.7 \% \\
\end{array}$ & $\begin{array}{l}\text { Post-survey } \\
14.3 \%\end{array}$ & $\begin{array}{l}\text { Pre-survey } \\
7.7 \% \\
\end{array}$ & $\begin{array}{l}\text { Post-survey } \\
4.8 \%\end{array}$ \\
\hline
\end{tabular}

Performance Based Data: Analysis of Final Unit Plans

Text, coding, and analysis of participants' culminating projects revealed that over the course of the intensive Summer Institute experiences - weeklong workshops, practice teaching, and online synthesis and application, participants had in fact integrated $21^{\text {st }}$ Century Skills into the conceptual framework used for their instructional planning.

Among the participants, the incorporation of $21^{\text {st }}$ century skills focused primarily on communication, collaboration and culture, areas traditionally addressed by foreign language classrooms. However, a number of participants explicitly or implicitly incorporated important skills related to technology, critical media literacy, creativity, and leadership. A full presentation of skill areas addressed is presented in Table 2.2. 
TABLE 2.2

$21^{\text {ST }}$ Century Skill AREAS AdDRESSED IN 2012 CUlminAting PROJECTS

\begin{tabular}{|c|c|c|c|}
\hline & & Arabic Teachers & Chinese Teachers \\
\hline \multirow{7}{*}{$\begin{array}{l}\text { Information, Media and } \\
\text { Technology Skills }\end{array}$} & Communication & & $100 \%$ \\
\hline & Collaboration & & $100 \%$ \\
\hline & Critical Thinking/Problem Solving & & $60 \%$ \\
\hline & Creativity and Innovation & & $50 \%$ \\
\hline & Information Literacy & & $50 \%$ \\
\hline & Media Literacy & & $50 \%$ \\
\hline & Technology Literacy & & $60 \%$ \\
\hline \multirow[t]{5}{*}{ Life and Career Skills } & Flexibility and Adaptability & & $30 \%$ \\
\hline & Initiative and Self-Direction & & $20 \%$ \\
\hline & Social and Cross-Cultural Skills & & $100 \%$ \\
\hline & Productivity and Accountability & & $30 \%$ \\
\hline & Leadership and Responsibility & & $50 \%$ \\
\hline
\end{tabular}

It is interesting to note that the areas which are the newest yet most commonly experienced in U.S. foreign language teaching settings - communicative and collaborative approaches - were the most common $21^{\text {st }}$ Century Skills addressed, along with social and cross cultural skills, which serve as an area of strong value added by these native speakers of Chinese and Arabic. The fact that the less familiar skills - and those newest in foreign language teaching settings - were less commonly addressed. These data seem to suggest that ongoing training in order to consolidate incorporation of $21^{\text {st }}$ Century Skills into critical need language teaching would benefit in-service teachers of such languages.

Research Question 2: How do teacher participants utilize technology applications to implement $21^{\text {st }}$ Century Skills in today's world language classroom?

In the pre-institute survey only $20 \%$ of the teachers said they use technology in their classrooms. While this is a small percentage, it is interesting to note that the teachers were comfortable and skillful at using the online platform, Ning. The online portion of the summer institute was specifically designed to allow participants to engage with their colleagues in both English and/or Chinese and Arabic. The data demonstrated that teachers were actively engaged in the discussions and that they particularly enjoyed the communication across languages and cultures. Conversation threads illustrated how teachers shared ideas about how to utilize technology applications to implement the $21^{\text {st }}$ Century Skills. They also revealed that they were grateful for the opportunity to get feedback from the master teachers as well as the online instructor. The teachers commented on the wealth of ideas that were shared and how useful they found them.

While discussing their roles and participation in an online community of learners, the teachers revealed in the preinstitute survey how much they looked forward to connecting and learning from others as well as sharing, technology applications, lesson plans and resources. After using Ning during the summer institute, the participants felt that the online community was very helpful for getting feedback from peers, as well as building strong relationships with other teachers. However, many felt that Ning could sometimes be overwhelming.

When discussing how Ning impacted their teaching and ability to use of technology applications to connect to the $21^{\text {st }}$ Century Skills, many believed that it could serve as a model for them to develop more student-centered instruction, using technology in the classroom and having an online form platform where students can stay connected. In their online discussions, teachers shared resources as well as continuously gave feedback to each other on materials and lesson plans posted both in the target language and English.

The teacher participants also identified the following technology tools as those they frequently use:

- YouTube

- SmartBoard

- PowerPoint

- Authentic videos

- Skype

- Critical thinking games

- Media literacy

Many of the teacher participants readily acknowledged that they feared going into classrooms where their students were more technologically savvy than they were. The notion of using technology applications to implement $21^{\text {st }}$ Century Skills was both interesting and challenging and they were excited to learn about this topic.

Performance Based Data: Analysis of Final Unit Plans

Performance-based data show a dramatic contrast between reported incorporation of technology and actual intended implementation. Final projects from week 2 (presented in Table 2.3) reveal that the all of the teachers who submitted final projects were able to incorporate technology. However, their uses are limited, in the majority, to basic presentation of PowerPoint and video, both for students and teachers. Most notably, no one used blogging, audio blogging, or other authentic communication tools. This demonstrates that technology incorporation is a critical area for critical need language teachers in U.S. schools. 
TABLE 2.3

TECHNOLOGY APPLICATIONS IN FINAL PROJECTS

\begin{tabular}{|c|c|c|c|c|}
\hline & \multicolumn{2}{|l|}{ Arabic Teachers } & \multicolumn{2}{|l|}{ Chinese Teachers } \\
\hline $\begin{array}{l}\text { Percentage using } \\
\text { technology in applied } \\
\text { teaching products }\end{array}$ & $100 \%$ & & $100 \%$ & \\
\hline Technology & Teacher-applications & Student-applications & Teacher-applications & Student-applications \\
\hline PowerPoint & $66 \%$ & $33 \%$ & $50 \%$ & $10 \%$ \\
\hline Wordle & - & $33 \%$ & - & - \\
\hline Webquest/internet & - & $33 \%$ & - & $20 \%$ \\
\hline Video clips & - & - & $30 \%$ & - \\
\hline Video production & - & - & - & $20 \%$ \\
\hline Podcast & - & - & - & $10 \%$ \\
\hline Smartboard & - & - & $10 \%$ & - \\
\hline
\end{tabular}

\section{Implications and Limitations}

One implication portrayed in this study indicates that multiple efforts and pathways need to be taken to provide professional development training for filling the paucity of critical need language teachers. A second implication inherent in this study is the need for recognition and acknowledgement that many challenges confront these teachers transitioning into teaching in U.S. schools. The ACTFL $21^{\text {st }}$ Century Skills Map helps to better equip and prepare students for a global community. It is clear that the teacher participants grasped the salient ideas and concepts and quickly adapted them to connect to their instructional practices.

There are a few notable limitations when considering the results and implications of this study. First, the researchers opted to use open-ended questions on the pre- and post-institute surveys. Although this was done to provide the participants with complete autonomy in their responses, it may have limited the type of data collected. Also, it is quite possible that not all questions were understood and/or comprehensible as the surveys were entirely in English. A second limitation is that the researchers were not able to fully utilize a broad range of data sources. Further research should include classroom observations and follow-up interviews in order to clarify and extend one's understanding of the relationships that emerged from the data in this small-scale study. Third, the small sample size may not be representative of the larger population of teachers of critical need languages. Therefore, generalizing the findings from this study should be done so with caution.

\section{CONCLUSION}

This study is descriptive in nature, with its aim being to build upon our previous line of inquiry. Because the sample size is small, it is difficult to make generalizations. However, the study clearly demonstrates the multifaceted training requirements of critical need language teachers. The data collected in this fifth year of the GMU StarTalk summer institute adds to a much needed growing body of research. The study was designed as a continuation of on-going efforts to investigate filling the gap between supply and demand of critical need language teachers. Due to the urgent need to expand the teaching force in critical need languages, and the challenges of teaching Arabic and Chinese in U.S. schools, we must focus on developing new programs at all levels while increasing enrollments in existing programs. Integrating the $21^{\text {st }}$ Century Skills Map into critical language teaching provides a significant step forward in seeking to develop U.S. students into highly skilled world citizens. It is our hope that this research may serve as a model for increasing the numbers of teachers in high need areas, such as Arabic and Chinese.

\section{APPENDix A PRE AND Post-SURVeY Questions}

1. What is your home country?

2. What is your gender?

3. What is the highest degree that you have earned?

4. Do you have teaching experience? - Yes - No

- What subject(s) did you teach?

- What grade(s)?

- Where (country)?

- For how long?

5. Do you currently hold a foreign/ world language teaching license or certificate in the United States?

- If you do not hold a teaching license in the U.S., are you currently working on the licensure requirements?

6. Are you employed as a language teacher in a U.S. school? - yes - no

- public school

- private school

7. What language(s) do you teach or will you teach?

- Chinese

- Arabic

8. Check the statement that best describes your familiarity with 21 st century skills: 
- I have heard of 21 st century skills and am familiar with how to address them

- I have heard of 21 st century skills but I am not sure how to address them

- I have never heard of the term 21 st century skills

9. From your experience, what are some ways teachers can help students learn a language?

10. What do you believe a teacher's role is in the classroom?

11. What technology applications are you currently using in the classroom?

12. Check the statement that best describes your knowledge and understanding of learner-centered instructional practices:

- I know about learner-centered instructional practices well enough to apply them to my teaching

- I know about learner-centered instructional practices, but I am not sure how to apply them in my teaching

- I have heard of learner-centered instructional practices, but I do not know much about them

- I have never heard of learner-centered instructional practices

13. Check the statement that best describes your knowledge and understanding of the Standards of Foreign Language Learning (The 5Cs):

- I know the standards well enough to apply them to my teaching

- I know the standards, but I am not sure how to apply them in my teaching

- I have heard of the standards, but I do not know much about them

- I have never heard of the standards

14. Check the statement that best describes your knowledge and understanding of the 3 Communicative Modes (interpretive, interpersonal, presentational):

- I know the 3 Communicative Modes well enough to apply them to my teaching

- I know the 3 Communicative Modes, but I am not sure how to apply them in my teaching

- I have heard of the 3 Communicative Modes, but I do not know much about them

- I have never heard of the 3 Communicative Modes

15. Please rate the following concerns about teaching U.S. students:

Not a concern for me An occasional concern for me A moderate concern for me A great concern for me

- Using the target language during my instruction

- Motivating students to use the target language

- Getting students to care about my class

- Creating interesting activities for my students

- Talking to a student who is not behaving in class

- Using technology in my lessons

- Getting students to participate in small group activities

- Creating an integrated performance-based assessment

- Evaluating a performance-based assessment

- Talking to a parent/guardian about a student's grade

16. What do you hope to learn/gain from this StarTalk workshop?

17. What do you hope to gain from an online community?

\section{APPENDIX B POST-TEACHING SimULATION GROUP INTERVIEW}

1. Why did you choose your lesson theme or topic?

What kinds of activities did you plan?

How were they learner-centered?

How did your activities connect with the standards?

Did you connect with the $21^{\text {st }}$ Century Skills? How?

Did you incorporate any technology?

2. What worked well during your instruction? Why do you think it worked well?

3. What did not work so well during your instruction? Why do you think it didn't work well?

4. What would you do differently the next time you try these kinds of activities?

5. How did you gauge student comprehension?

6. What did you learn about yourself as a teacher?

7. What did you learn about U.S. students?

8 . Were your objectives met? Why, or why not?

9. Overall, how do you feel about the lesson(s) you taught?

\section{APPENDIX C ONLINE Discussion PROMPTS}

Day 1: Moving toward learner-centeredness 
Please view the short video clip titled "Student Centered Language Classroom" (the third button on the right side of the screen) at: http://startalk.umd.edu/teacher-development/workshops/2009/CTCLI/content/index.php

1. Do you think learner-centered instruction is more beneficial than teacher-centered instruction? Why or Why not? Please provide details or a specific example.

2. What 3 elements of planning learner-centered activities are most challenging for you? Why? How can you overcome these?

3. Many teachers find that getting students to use the target language (instead of English) is a challenge. Why do you think students are so reluctant to speak Arabic or Chinese in class? What can teachers do to motivate students to use the target language in class? Please provide 3 examples.

Day 2: Applying standards and the ACTFL $21^{\text {st }}$ Century Skills Map in a learner centered classroom Please view the video at the Tab 2 "Standards and the Journey" at: http://media.startalk.umd.edu/workshops/2009/Rutgers/video_2.php

1. How do you think that the ACTFL 21st Century Skills Map works with learner-centered instruction? Why and how?

2. Many language teachers believe that you cannot teach a language without teaching the cultures where that language is spoken. What does "teaching culture" mean to you? How can teaching culture fit in with the standards of learning in your school?

3. Please view the video at Tab 3 "Instruction in Meaningful Contexts" at http://media.startalk.umd.edu/workshops/2009/Rutgers/video_3.php

4. What elements of Rebecca Wang's instruction can you incorporate into your classroom? Please select 3.

Day 3: Learner centeredness and classroom management

1. Creating a classroom environment for learner-centered instruction requires good classroom management. What advice would you give to someone who has never used learner-centered instruction, but who wants to give it a try?

2. There always seems to be one or two students who just don't care about learning a language. They are usually the ones to disrupt a good lesson. You know that if you keep sending them to the office, it will look like you are not able to manage your classroom. What can you do to get these disruptive students to behave and participate in your lessons?

3. Go to: http://startalk.umd.edu/teacher-development/workshops/2009/CTCLI/content/index.php Choose "Cooperative Learning Activities" (the $5^{\text {th }}$ button on the right side of the screen) then preview one video from each type of activity: paired activities, small group activities, whole class activities, and more activities. Preview each of these four videos then answer these questions:

- How can you use these activities to help you manage your classroom to optimize learning?

- What types of classroom management techniques will you need to use in order to include these activities in your own teaching? Please describe 3 techniques.

Day 4: Millennial learners; closing the instructional gaps

1. Please reflect on what you have learned so far in the STSI and how this is going to change or modify your teaching practices to address the $21^{\text {st }}$ century skills

Day 5: Cultural understandings of teachers' roles

1. Please reflect on what you think the impact of your cultural understanding of teacher roles has on your classroom practices in the US.

Day 6: Personal and professional development

1. What impact do you think this might have on your teaching practices in the US?

\section{REFERENCES}

[1] American Council on the Teaching of Foreign Languages. (ACTFL, 2011). ACTFL 21 ${ }^{\text {st }}$ Century Skills Map. Retrieved February 4, 2013 http://www.p21.org/storage/documents/Skills\%20Map/p21_worldlanguagesmap.pdf.

[2] Banks, J. A. (2006). Cultural diversity and education: Foundations, curriculum, and teaching. Boston: Pearson

[3] Brecht, R., Golonka, E., Rivers, W., \& Hart, M. (2007). Language and critical area studies after September 11: An evaluation of the contributions of Title VI/F-H to the national interest. College Park, MD: The National Foreign Language Center.

[4] Committee for Economic Development. (2006). Education for global leadership: The importance of international studies and foreign language education for U.S. economic and national security. Retrieved January 10, 2013, from http://www.ced.org.

[5] Davidson, D. (2010). Federal Investment in The Academic And Educational Sector: Producing The Expertise, Teachers, And Programs For World Languages. Testimony before the US Senate Committee on Homeland Security and Governmental Affairs Subcommittee on Oversight of Government Management, the Federal Workforce, and the District of Columbia on "Closing the Language Gap: Improving the Federal Government's Foreign Language Capabilities,” July 29, 2010.

[6] Duncan, A. (2010). “America's Foreign Language Deficit.” Retrieved February 10, 2013, from http://www.forbes.com/fdc/welcome_mjx.shtml.

[7] Homeland Security and Governmental Affairs Subcommittee (2012). "Subcommittee on investigations." Retrieved February 10, 2013 from http://www.hsgac.senate.gov/subcommittees/investigations/media?year=2012.

[8] Hui, X. (2012). Challenges native Chinese teachers face in teaching Chinese as a foreign language to non-native Chinese students in U.S. classrooms. Theses, Student Research, and Creative Activity: Department of Teaching, Learning and Teacher Education. Retrieved January 19, 2013, from http://digitalcommons.unl.edu/teachlearnstudent/20.

[9] Hall Haley, M., \& Alsweel, R.A. (2012). Bridging Instructional Gaps in Preparing to Teach Millennial Language Learners. Theory and Practice in Language Studies, 2, 865-876. 
[10] Hall Haley, M., \& Ferro, M.S. (2011). Understanding the perceptions of Arabic and Chinese teachers towards transitioning into U.S. Schools. Foreign Language Annals, 44, 289-307.

[11] Hall Haley, M. (2001). Understanding learning-centered instruction from the perspective of multiple intelligences. Foreign Language Annals, 34, 355-367.

[12] Hammadou, J.A., \& Bernhardt, E.B. (1987). On being and becoming a foreign language teacher. Theory into Practice, 26, 301306.

[13] Ingold, C. W., \& Wang, S. C. (2010). The teachers we need: Transforming world language education in the United States. College Park, MD: National Foreign Language Center at the University of Maryland. Retrieved March 4, 2013, from: http://www.nflc.org/publications/the_teachers_we_need.pdf.

[14] Johnson, S. D. (1997, Spring). Will our research hold up under scrutiny? Journal of Industrial Teacher Education, 32(3), 3-6.

[15] Ladson-Billings, G. (2001). Crossing over to Canaan: The journey of new teachers in diverse classrooms. San Francisco: Jossey-Bass.

[16] McNamara. O, Lewis. S. (2004). The Recruitment of Overseas Trained Teachers. The University of Manchester and John Howson Education Data Surveys.

[17] Obama, B. (2008). Barack Obama: The War We Need to Win. Retrieved January 20, 2013, from http://www.barackobama.com/pdf/CounterterrorismFactSheet.

[18] O'Connell, M. E., \& Norwood, J. L. (2007). International education and foreign languages: keys to securing America's future. National Academy Press.

[19] Patton, M. Q. (2002). Qualitative evaluation and research methods (3rd ed.). Thousand Oaks, CA: Sage Publications, Inc.

[20] Rivers, W. P., \& Robinson, J. P. (2012). The Unchanging American Capacity in Languages Other Than English: Speaking and Learning Languages Other Than English, 2000-2008. The Modern Language Journal, 96(3), 369-379.

[21] Schrier, L. L. (1993). Preparing teachers of critical languages for the precollegiate environment. Theory into Practice, 33(1), 53-59.

[22] Taha. T.A. (2007). Arabic as "a critical-need" foreign language in post-9/11 era: A study of student's attitudes and motivation. Journal of Instructional Psychology, 34, 11-17.

[23] U.S. Department of Education. (2008). Enhancing foreign language proficiency in the United States: Preliminary results of the National Security Language Initiative. Office of Postsecondary Education. Retrieved January 20, 2013, from http://www.ed.gov/about/inits/ed/competitiveness/nsli.

[24] Valdes, J. M. (1986). Culture bound: Bridging the cultural gap in language teaching. Cambridge: Cambridge University Press.

Marjorie Hall Haley is tenured Professor of Education and Director of Foreign Language Teacher Licensure in the Graduate School of Education at George Mason University in Fairfax, VA. She is a former Spanish, French, German, and ESL teacher of 14 years. Dr. Haley holds a PhD in Foreign Language Education and English as a Second Language from the University of Maryland, College Park. She has also earned a Master's degree in education and advanced studies certificates from Towson University and Johns Hopkins University, respectively. In her 25th year at George Mason University, she teaches Foreign Language methods and ESL methods courses as well as doctoral courses in Brain-compatible Teaching and Learning, Bilingualism and Second Language Acquisition Research. She is actively involved in ongoing action research projects with teachers at local, national, and international levels. She has conducted four international teacher action research studies focused on the impact of implementing the Multiple Intelligences theory in foreign/second language classes. These studies included over 3,000 students in 14 states and 6 countries. In 2012, the Foreign Language Association of Virginia (FLAVA) awarded her its Marshall Brannon Excellence in Teaching Award, Post-Secondary. In 2002 George Mason University awarded her its Outstanding Faculty Award in Teaching. She currently serves as member of the Board of Directors of the American Council on the Teaching of Foreign Languages (ACTFL). Dr. Haley's research and publication record is wide. Her most recent book is, Brain-compatible Differentiated Instruction for English Language Learners (2010).

Sherry L. Steeley - Dr. Sherry L. Steeley is a faculty member with the Center for Language Education and Development at Georgetown University. Her doctoral specialization is in language, culture, teacher identity, and multilingual/multicultural education. Dr. Steeley has extensive English language training experience in secondary, post-secondary, and graduate-level, and workplace English, as well as teacher education in the areas of culturally responsive instruction, constructivist approaches to language teaching, and curriculum design. Dr. Steeley has extensive experience with international teachers as program designer, instructor, and PI on both State Department and USAID -funded programs for educational exchange and teacher education. Prior to undertaking a full time career in education, Dr. Steeley was an economic officer with the U.S. Department of State; in addition to a PhD in Educ ation, Dr. Steeley holds an M.A. from the Johns Hopkins School of Advanced International Studies, has worked in Africa, South and East Asia, and Central Europe, and has studied six foreign languages.

Maryam Salahshoor is a third year PhD student majoring in Multilingual/Multicultural Education at George Mason University. She received her Bachelor's and Master's degrees in special education from Ferdosi University in Iran and the University of North Florida (UNF). She has a postgraduate professional license for teaching grades k-12 in Virginia and is highly qualified by the state in teaching math grades 6-12. She has worked as a special education teacher in grades (K-12) for eight years in various settings. Currently, she is working as a graduate research assistant in Multilingual/Multicultural education at George Mason University. She has been involved in several projects and grants that promote heritage language teaching and learning and academic success for ethnic minorities. She is fluent in Farsi and English. Her research interests are heritage language nee ds of ethnic minorities and issues related to identification and providing services to English language learners in special education. Her most recent co-authored book 
chapter is titled "Pedagogical diversity and the need for contextually responsive teacher education in the U.S" which appeared in Internationalizing Teachers' Education in the U.S. 